\title{
Interstitial Transudate Purines in Normoxic and Hypoxic Immature and Mature Rabbit Hearts
}

\author{
G. PAUL MATHERNE, JOHN P. HEADRICK, SHARON D. COLEMAN, AND ROBERT M. BERNE
}

Departments of Pediatrics and Physiology, University of Virginia Health Sciences Center, Charlottesville, Virginia 22908

\begin{abstract}
Interstitial transudate and coronary venous concentrations of adenosine, inosine, and hypoxanthine were determined in isolated isovolumic immature and mature rabbit hearts during normoxia and hypoxia. During normoxia, interstitial transudate adenosine was lower in immature hearts compared with mature hearts. Interstitial transudate concentrations of adenosine, inosine, and hypoxanthine were $130 \pm 16 \mathrm{nM}, 699 \pm 88 \mathrm{nM}$, and $392 \pm$ $80 \mathrm{nM}$, respectively, in immature rabbit hearts and $228 \pm$ $35 \mathrm{nM}, 1154 \pm 126 \mathrm{nM}$, and $287 \pm 30 \mathrm{nM}$, respectively, in mature rabbit hearts. Interstitial transudate adenosine was significantly lower in the immature hearts. Coronary venous purine concentrations were 6- and 8-fold lower than their respective interstitial transudate concentrations during normoxia in both age groups. Hypoxia significantly increased interstitial transudate purines in both age groups. Interstitial transudate adenosine, inosine, and hypoxanthine increased to $1180 \pm 231 \mathrm{nM}, 4049 \pm 500 \mathrm{nM}$, and $1099 \pm 98 \mathrm{nM}$, respectively, in immature hearts and to $1225 \pm 300 \mathrm{nM}, 5220 \pm 1217 \mathrm{nM}$, and $876 \pm 147 \mathrm{nM}$, respectively, in mature hearts. The age-related difference in transudate adenosine levels present during normoxia was not detected during hypoxia. Venous purine levels increased during hypoxia and the gradient from interstitial transudate fluid to venous effluent was abolished for adenosine in both groups. In immature hearts, hypoxia led to higher venous effluent adenosine levels than in the mature hearts. Coronary resistance correlated with interstitial transudate adenosine in both groups, although immature hearts displayed lower resistances at all adenosine levels. The results indicate that 1 ) interstitial transudate adenosine may regulate coronary resistance during hypoxia in isolated hearts from both age groups, 2) age-related differences exist in the normoxic release of interstitial transudate adenosine, and 3) age-related differences appear to be present in the release of purines into the coronary venous effluent during hypoxia. (Pediatr Res 28: 348-353, 1990)
\end{abstract}

\section{Abbreviations}

AoP, aortic pressure

EDP, end diastolic pressure

LVP, left ventricular systolic pressure

$\mathrm{dP} / \mathrm{dt}$, first derivative of ventricular pressure

HR, heart rate

$\mathrm{MVO}_{2}$, oxygen consumption

$\mathrm{P}_{\mathrm{a}} \mathrm{O}_{2}$, perfusate partial pressure of $\mathrm{O}_{2}$

Received December 14, 1989; accepted May 21, 1990

Correspondence and reprints requests: G. Paul Matherne, M.D., Assistant Professor, Department of Pediatrics, Division of Pediatric Cardiology, Box 386, University of Virginia Health Sciences Center, Charlottesville, VA 22908.

Supported by a grant from the American Heart Association, Virginia Affiliate, Inc, a grant from the Thomas F. Jeffress and Kate Miller Jeffress Memorial Trust, and USPHS grant HL 10384. J.P.H. was supported by a fellowship from the American Heart Association, Virginia Affiliate, Inc.
$\mathrm{P}_{\mathrm{v}} \mathrm{O}_{2}$, effluent partial pressure of $\mathrm{O}_{2}$

Adenosine is thought to be an important metabolic regulator of coronary blood flow (1). The link between myocardial metabolism and adenosine release is not firmly established, although changes in the ratio of oxygen supply to myocardial demand and the cytosolic phosphorylation potential have been implicated (2, 3 ). The relationship between the phosphorylation potential and myocardial oxygen consumption changes during maturation in vivo (4). Portman et al. (4) found that the cytosolic phosphorylation potential decreased in immature sheep hearts during norepinephrine infusion, whereas it remained unchanged in the mature heart.

Because changes in myocardial energy metabolism occur during growth and maturation, and because it has been shown that adenosine formation and coronary blood flow are closely linked to high-energy phosphate levels (5-7), it is a reasonable hypothesis that developmental differences in myocardial adenosine production and flow regulation may exist. A study by Toma et al. (8) examined this hypothesis in the developing guinea pig heart and demonstrated greater coronary venous adenosine release in adult hearts than in immature hearts during norepinephrine infusion. In a preliminary study, Jimenez et al. (9) reported greater total myocardial adenosine nucleoside levels in adult rabbit hearts than in immature rabbit hearts following ischemia. Both of these studies utilize indirect indices of myocardial adenosine formation. Venous effluent adenosine underestimates interstitial adenosine levels because the endothelium avidly takes up and metabolizes adenosine $(10,11)$. The method of measuring total myocardial adenosine levels used by Jimenez et al. (9) overestimates interstitial adenosine, inasmuch as most of the myocardial adenosine is bound intracellularly $(12,13)$.

A new technique for estimating interstitial fluid adenosine levels has been developed in this laboratory using porous nylon disks placed on the epicardial surface of the heart to equilibrate with the interstitial transudate, which is an index of myocardial interstitial fluid (14-19). This technique was used to examine the effects of severe hypoxia on interstitial transudate adenosine, inosine and hypoxanthine levels in isolated hearts from immature and mature rabbits. Venous purines were also determined.

\section{MATERIALS AND METHODS}

Isolated perfused hearts. Ten immature (age 2-4 wk, wt 269 $\pm 12 \mathrm{~g}$ ) and 11 mature (age 4-6 mo) $(20-22)$ (wt $2657 \pm 172 \mathrm{~g}$ ) New Zealand White rabbits were anesthetized with ketamine and xylazine $(50 \mathrm{mg} / \mathrm{kg}$ and $5 \mathrm{mg} / \mathrm{kg}$ intramuscularly, respectively). A tracheostomy was performed, and positive pressure ventilation with $100 \% \mathrm{O}_{2}$ was initiated. A thoracotomy was then performed and both right and left superior venae cavae and the inferior vena cava were ligated. The hearts were removed and 
placed directly into cold perfusion fluid before aortic cannulation and retrograde perfusion. Total ischemic time from removal of the heart to the onset of retrograde coronary perfusion was less than $30 \mathrm{~s}$. Hearts were perfused in the nonrecirculating Langendorff mode at a flow rate of $10.0 \pm 0.7 \mathrm{~mL} / \mathrm{min} / \mathrm{g}$ ventricular tissue for immature hearts and $8.0 \pm 0.4 \mathrm{~mL} / \mathrm{min} / \mathrm{g}$ ventricular tissue for mature rabbit hearts. Constant flow was maintained with a peristaltic pump. Constant coronary flow was used to exclude flow-dependent changes in nucleoside release and uptake, and to provide a constant oxygen delivery during each experimental period $(23,24)$. The hearts were perfused with a modified Krebs-Henseleit bicarbonate buffer containing (in $\mathrm{mmol} / \mathrm{L}): \mathrm{NaCl} 122, \mathrm{KCl} 4.7, \mathrm{CaCl}_{2} 2.5, \mathrm{MgSO}_{4} 1.2, \mathrm{NaHCO}_{3}$ $22, \mathrm{KH}_{2} \mathrm{PO}_{4} 1.2$, and glucose 11 . The buffer was equilibrated with $95 \% \mathrm{O}_{2}, 5 \% \mathrm{CO}_{2}$ at $37^{\circ} \mathrm{C}$, giving a $\mathrm{pH}$ of $7.38 \pm 0.004$, $\mathrm{PCO}_{2} 34 \pm 1$, and $\mathrm{PO}_{2} 586 \pm 8$. Once the hearts were cannulated and perfused, excess tissue was trimmed away and the pulmonary artery was cannulated for collection of venous effluent and to prevent leakage of venous fluid onto the ventricular surface. Preliminary experiments with fluorescein-labeled dextran demonstrated no contamination of the ventricular surface with effluent in hearts in which the caval veins were ligated and the pulmonary artery cannulated as described above. A thin-walled fluid-filled latex balloon was inserted into the left ventricle via the mitral valve. A left ventricular vent was placed through the ventricular apex to allow drainage of thebesian venous flow. End diastolic pressure was adjusted to $6-8 \mathrm{~mm} \mathrm{Hg}$. Hearts were then placed in a water-jacketed chamber for control of temperature and humidity.

Hemodynamic monitoring. AoP was monitored by a fluidfilled line attached to a port located $1 \mathrm{~cm}$ above the aortic cannula. This line was connected to a Spectramed Statham P23 $\mathrm{XL}$ pressure transducer (Gould, Inc., Oxnard, CA) and the pressure signal was amplified by a Gould transducer amplifier. Left ventricular pressure was monitored by attaching the ventricular balloon to a Spectramed Statham P23 XL pressure transducer connected to a Gould pressure processor transducer (Gould Electronics, Cleveland, $\mathrm{OH}$ ), which provides both direct pressure output along with LVP and EDP. The $\mathrm{dP} / \mathrm{dt}$ was obtained with a Gould differentiator. HR was monitored with a Gould Biotach amplifier triggered on the left ventricular pressure wave. Coronary flow was measured with a Transonics T101 ultrasonic flowmeter (Transonic Systems, Inc., Ithaca, NY) using a Transonics $2 \mathrm{~N} 110$ cannulating flow probe placed in-line above the aortic cannula. The difference between the perfusate and effluent partial pressure of $\mathrm{O}_{2}\left(\mathrm{P}_{\mathrm{a}} \mathrm{O}_{2}\right.$ and $\mathrm{P}_{\mathrm{v}} \mathrm{O}_{2}$, respectively) was measured with two in-line Instech 105/05 oxygen electrodes (Instech Laboratories, Horsham, MA) and a YSI Model 5300 Biological Oxygen Monitor (Yellow Springs Instrument Co., Yellow Springs, OH) (8). Both flowmeter and oxygen meter electrode signals were amplified by Gould Universal amplifiers. AoP, HR, LVP, EDP, coronary flow, $\mathrm{P}_{\mathrm{a}} \mathrm{O}_{2}-\mathrm{P}_{\mathrm{v}} \mathrm{O}_{2}$ difference and $\mathrm{dP} / \mathrm{dt}$ were recorded continuously with a Gould RS 3800 thermal recorder. The amplified analog signals were then converted to digital signals by a Metrabyte DAS- 16 analog to digital conversion board (Metrabyte Corp., Taunton, MA) connected to an IBM AT computer (IBM Instruments, Inc., Danbury, CT). Data were collected with Labtech Notebook (Laboratory Technologies Corp., Wilmington, MA), an on-line data acquisition and analysis program (25), which then calculated the coronary vascular resistance (AoP/coronary flow), rate pressure product (HR $\times$ LVP), and oxygen consumption $\left(\mathrm{MVO}_{2}\right) . \mathrm{MVO}_{2}$ was calculated as:

$\mathrm{MVO}_{2}(\mu \mathrm{L} \mathrm{O} / \mathrm{min} / \mathrm{g})=$

$$
\left(\mathrm{P}_{\mathrm{a}} \mathrm{O}_{2}-\mathrm{P}_{\mathrm{v}} \mathrm{O}_{2}\right) \times \text { coronary flow } \times(\mathrm{c} / 760)
$$

where $\mathrm{P}_{\mathrm{a}} \mathrm{O}_{2}$ and $\mathrm{P}_{\mathrm{v}} \mathrm{O}_{2}$ refer to perfusate and venous effluent $\mathrm{PO}_{2}$ (mm HG), respectively, and $\mathrm{c}=0.0239$ (Bunsen solubility coefficient of oxygen dissolved in perfusate at $37^{\circ} \mathrm{C}, \mathrm{mL} \mathrm{O}_{2} / \mathrm{atm} /$ $\mathrm{mL})(8)$.
Epicardial disc technique. Epicardial discs (6-mm diameter) were cut from sheets of porous hydrophilic MicroSep Magna Nylon 66 Membrane Filters (Micron Separation, Inc., Westboro, MA) with a pore size of $0.45 \mu$, as described previously (14). Discs were weighed before soaking in Krebs solution and two wetted discs were applied to the epicardial surface of the left ventricle and left in place for $2 \mathrm{~min}$ to allow equilibration of disc fluid with the interstitial transudate fluid. The discs were then removed, reweighed to determine disc sample volume, and stored in vials at $-80^{\circ} \mathrm{C}$ until analyzed for purines by HPLC.

HPLC analysis. Discs were thawed and placed in $200-400 \mu \mathrm{L}$ of distilled water to elute the contents over $60 \mathrm{~min}$. Recovery of applied adenosine was $>94 \%$. The diluted samples were filtered $(0.2 \mu)$ in Spin-X tubes (Costar Inc., Cambridge, MA) with the aid of centrifugation and then placed in HPLC tubes. One hundred to $200 \mu \mathrm{L}$ of this sample or filtered undiluted venous effluents were injected onto a C-18 reverse-phase column (Supelco LC18S; Supelco, Inc., Bellefonte, PA) and then eluted using a linear 30 -min buffer gradient $\left(100 \mathrm{mM} \mathrm{KH}_{2} \mathrm{PO}_{4}, 1 \%\right.$

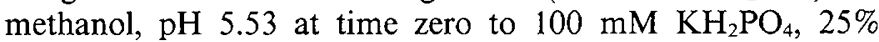
methanol, pH 5.58 at $23 \mathrm{~min}$ ) at $1.3 \mathrm{~mL} / \mathrm{min}$. Absorbance was continuously monitored at $254 \mathrm{nM}$ with a Kratos model 773 variable wavelength detector (Kratos Analytical Instruments, Ramsey, NJ). Peaks were quantitated by comparison of peak areas with those for standards. Standard curves were routinely run with each set of samples.

To exclude the possibility that adenosine deaminase activity interferes with adenosine determinations, nine diluted EPD samples were analyzed and then refrozen. The samples were subsequently thawed and incubated at room temperature for $12 \mathrm{~h}$ The samples were then reanalyzed. No loss of adenosine was detected in any of the samples, demonstrating that no significant adenosine deaminase activity was present.

Experimental protocol. Hearts were allowed to equilibrate for 30-40 min. After equilibration, interstitial transudate and venous effluent were sampled together with simultaneous continuous measurement of AoP, LVP, EDP, $\mathrm{HR}, \mathrm{dP} / \mathrm{dt}, \mathrm{MVO}_{2}$, resistance, and rate pressure product over two 5-min basal periods. The 5min experimental period allowed two consecutive 2 -min periods for collection of interstitial transudate fluid and venous effluent. Hypoxic perfusion was then initiated by changing to a perfusate equilibrated with $10 \% \mathrm{O}_{2}, 5 \% \mathrm{CO}_{2}$, and $85 \% \mathrm{~N}_{2}$ (resulting $\mathrm{pH}$ $7.38 \pm 0.01, \mathrm{PCO}_{2} 35 \pm 1$, and $\mathrm{PO}_{2} 91 \pm 2$ ). After $20 \mathrm{~min}$ of hypoxic perfusion, during which time stable function was achieved, two more experimental periods were performed as described above. Data from hearts were excluded if: 1 ) coronary effluent accounted for less than $90 \%$ of coronary flow, 2) aortic pressure was less than $60 \mathrm{~mm} \mathrm{Hg}$ in mature hearts or less than $40 \mathrm{~mm} \mathrm{Hg}$ in immature hearts (26), or 3) stable hemodynamic parameters were not obtainable.

After all experiments, hearts were weighed for determination of ventricular weight. In nine immature and nine mature rabbit experiments, hearts were dried and reweighed to obtain percentage water weight. To determine control percent water weight, four immature and six mature hearts were weighed and dried without undergoing an experiment.

Statistics. Unless stated otherwise, all values shown are means \pm SEM. Statistical comparisons between age and oxygen levels were made using a one-way analysis of variance with Bonferroni's correction for multiple comparisons. Comparisons between interstitial transudate and venous purine levels were made using paired $t$ test. A $p$ value of $<0.05$ was considered significant.

Animal care. All protocols were approved by the University of Virginia Animal Research Committee and were in accordance with National Institute of Health policies and the Guide for the Care and Use of Laboratory Animals (NIH Publication No. 8523, revised 1985). 


\section{RESULTS}

Myocardial water content. Immature hearts were $81 \pm 1 \%$ water by weight, similar to mature hearts, which were $80 \pm 3 \%$ water. During the experiment, both mature and immature hearts accumulated water. The mature heart increased to $87 \pm 1 \%$ water, whereas the immature heart only increased to $84 \pm 2 \%$ water.

Normoxic hemodynamics. EDPs were the same in both age groups (Table 1). Mature hearts had higher LVP, higher maximal $+\mathrm{dP} / \mathrm{dt}$, higher AoP, and higher coronary resistance than did the immature hearts, whereas immature hearts had a higher HR than the mature hearts (Table 1). $\mathrm{MVO}_{2}$, corrected for ventricular weight, was similar in each group, but mature hearts had a higher index of work (rate pressure product) (Table 1).

Normoxic purines. Interstitial transudate fluid levels of adenosine and inosine were lower in the immature heart, whereas hypoxanthine levels were not significantly different in immature and mature hearts (Table 2). A 5- to 7-fold concentration gradient from the interstitial transudate to venous effluent was found for adenosine and inosine in both age groups, whereas an 8-fold concentration gradient was found for hypoxanthine (Table 3 ). No age-related differences were present for venous adenosine and hypoxanthine levels (Table 2). Alternatively, venous inosine levels were significantly higher in mature hearts (Table 2).

Table 1. Hemodynamic parameters of immature and mature rabbit hearts*

\begin{tabular}{|c|c|c|c|c|}
\hline & \multicolumn{2}{|c|}{ Immature } & \multicolumn{2}{|c|}{ Mature } \\
\hline & Normoxia & Hypoxia & Normoxia & a Hypoxia \\
\hline HR (bpm) & $178 \pm 4 \dagger$ & $135 \pm 5 \ddagger$ & $164 \pm 4$ & $148 \pm 5 \ddagger$ \\
\hline $\mathrm{EDP}(\mathrm{mm} \mathrm{Hg})$ & $8 \pm 1$ & $11 \pm 1 \ddagger$ & $7 \pm 1$ & $13 \pm 2$ \\
\hline LVP (mm Hg) & $98 \pm 7 \dagger$ & $41 \pm 3+t$ & $138 \pm 3$ & $51 \pm 2 \ddagger$ \\
\hline $\mathrm{dP} / \mathrm{dt}\left(\mathrm{mm} \mathrm{Hg} / \mathrm{s} \cdot 10^{2}\right)$ & $14 \pm 1 \dagger$ & $6 \pm 1 \ddagger$ & $19 \pm 1$ & $6 \pm 0.3+$ \\
\hline $\begin{array}{l}\mathrm{RPP}(\mathrm{mm} \mathrm{Hg} / \mathrm{min} \text {. } \\
\left.\quad 10^{3}\right)\end{array}$ & $18 \pm 1 \dagger$ & $6 \pm 1+t$ & $23 \pm 1$ & $8 \pm 0.3$ \\
\hline $\mathrm{MVO}_{2}\left(\mu \mathrm{L} \mathrm{O} \mathrm{O}_{2} / \mathrm{min} / \mathrm{g}\right)$ & $113 \pm 13$ & $20 \pm 2 \ddagger$ & $97 \pm 7$ & $16 \pm 1 \neq$ \\
\hline $\begin{array}{l}\mathrm{R}(\mathrm{mm} \mathrm{Hg} / \mathrm{mL} / \\
\mathrm{min} \cdot \mathrm{g})\end{array}$ & $6 \pm 0.3 \dagger$ & $3 \pm 0.2 \uparrow t$ & $11 \pm 1$ & $6 \pm 0.5+$ \\
\hline $\mathrm{AoP}(\mathrm{mm} \mathrm{Hg})$ & $58 \pm 6 \uparrow$ & $29 \pm 2 \dagger+$ & $92 \pm 6$ & $51 \pm 3 \ddagger$ \\
\hline
\end{tabular}

$*$ Values shown are means \pm SEM $(n=10$ for immature hearts, $n=$ 11 for mature hearts). RPP, rate pressure product; $R$, resistance.

$\dagger$ Significant differences between immature and mature values $(p<$ $0.05)$.

$\ddagger$ Significant differences between normoxic and hypoxic values $(p<$ $0.05)$
Hypoxic hemodynamics. EDP increased to a similar degree with hypoxia in each group (Table 1). Hypoxia caused a greater decrease in LVP in mature hearts than in immature hearts, although it was still higher in mature hearts (Table 1). Hypoxia depressed maximal $+\mathrm{dP} / \mathrm{dt}$, although the mature hearts were more sensitive and the difference that existed during normoxia was abolished. AoP and coronary resistance was decreased in both age groups during hypoxia, but the mature hearts still displayed higher AoP and resistance than did immature hearts (Table 1). $\mathrm{MVO}_{2}$ was decreased to a similar extent in immature and mature hearts. Hypoxia decreased the work index (ratepressure product) in each group, although the mature hearts continued to have a higher work index (Table 1). HR was also decreased by hypoxia in immature and mature hearts, but the decrease was more pronounced in the immature heart (Table 1).

Hypoxic purines. All purine levels increased during hypoxia, and the interstitial transudate levels of adenosine, inosine, and hypoxanthine were similar in both age groups (Table 2). Thus, the age-related differences in transudate adenosine and inosine, present during normoxia, were not detected during hypoxia. Hypoxic venous effluent purine levels increased to a greater degree in immature hearts compared with mature hearts (Table 2 ), leading to significantly higher venous levels of all purines in the immature heart. Thus, there were age-related differences in the venous release of purines during hypoxia. The concentration gradient from the interstitial transudate fluid to the venous effluent was reduced to unity for adenosine in both immature and mature hearts (Table 3). The concentration gradient for hypoxanthine was significantly reduced by hypoxia in both age groups (Table 3). Alternatively, the transudate to venous gradient for inosine was significantly reduced by hypoxia only in immature hearts (Table 3).

Coronary vascular resistance correlated with interstitial transudate adenosine in immature and mature hearts during normoxia and hypoxia (Fig. 1). An exponential dose-response relationship was found in each group, but immature hearts displayed significantly lower resistance at all interstitial transudate fluid adenosine levels.

\section{DISCUSSION}

The role of adenosine in the metabolic regulation of coronary blood flow remains controversial because no direct method for determining interstitial adenosine levels exists. We have used porous discs applied to the epicardial surface to sample interstitial transudate, which is reported to be a very close approximation of interstitial adenosine levels (14-19). Using this technique, we

Table 2. Interstitial transudate and coronary venous purine concentrations in normoxic and hypoxic immature and mature rabbit hearts*

\begin{tabular}{|c|c|c|c|c|}
\hline \multirow[b]{2}{*}{ Purine } & \multicolumn{2}{|c|}{ Immature } & \multicolumn{2}{|c|}{ Mature } \\
\hline & $\begin{array}{c}\text { Normoxia } \\
(\mathrm{nM})\end{array}$ & $\begin{array}{c}\text { Hypoxia } \\
(\mathrm{nM})\end{array}$ & $\begin{array}{c}\text { Normoxia } \\
\text { (nM) }\end{array}$ & $\begin{array}{l}\text { Hypoxia } \\
(\mathrm{nM})\end{array}$ \\
\hline \multicolumn{5}{|l|}{ Adenosine } \\
\hline Transudate & $130 \pm 16 \neq \S$ & $1180 \pm 231 \dagger$ & $228 \pm 35 \S$ & $1225 \pm 300 \dagger$ \\
\hline Venous & $30 \pm 9$ & $1389 \pm 207+t$ & $61 \pm 13$ & $836 \pm 102 \dagger$ \\
\hline \multicolumn{5}{|l|}{ Inosine } \\
\hline Transudate & $699 \pm 88 \mp \S$ & $4049 \pm 500 \dagger \S$ & $1154 \pm 126 \S$ & $5220 \pm 1217+\S$ \\
\hline Venous & $134 \pm 26 \neq$ & $1589 \pm 188 \dagger \dagger$ & $223 \pm 23$ & $705 \pm 78 \dagger$ \\
\hline \multicolumn{5}{|l|}{ Hypoxanthine } \\
\hline Transudate & $392 \pm 80 \S$ & $1099 \pm 98+\S$ & $287 \pm 30 \S$ & $876 \pm 147 \dagger \S$ \\
\hline Venous & $55 \pm 8$ & $476 \pm 58+\ddagger$ & $41 \pm 5$ & $185 \pm 16+$ \\
\hline
\end{tabular}

* Values shown are mean $\pm \operatorname{SEM}(n=10$ for immature hearts, $n=11$ for mature hearts).

+ Significant differences between normoxic and hypoxic values $(p<0.05)$.

$¥$ Significant differences between immature and mature values $(p<0.05)$.

$\S$ Significant differences between interstitial transudate and venous values $(p<0.05)$ 
Table 3. Interstitial transudate:coronary venous purine ratios during normoxia and hypoxia in immature and mature rabbit hearts*

\begin{tabular}{lcclll}
\hline & \multicolumn{2}{c}{ Immature } & & \multicolumn{2}{c}{ Mature } \\
\cline { 2 - 3 } \cline { 5 - 6 } \cline { 5 - 6 } & Normoxia & Hypoxia & & Normoxia & Hypoxia \\
\hline Adenosine & $7.7 \pm 1.7$ & $0.8 \pm 0.1 \dagger$ & & $6.9 \pm 2.5$ & $1.4 \pm 0.3 \dagger$ \\
Inosine & $6.1 \pm 0.9$ & $2.7 \pm 0.3 \dagger \dagger$ & & $5.4 \pm 0.6$ & $6.9 \pm 1.0$ \\
Hypoxanthine & $8.7 \pm 2.6$ & $2.7 \pm 0.4 \dagger$ & & $7.5 \pm 1.0$ & $4.6 \pm 0.6 \dagger$ \\
\hline
\end{tabular}

$*$ Values shown are means $\pm \operatorname{SEM}(n=10$ for immature, $n=11$ for mature hearts).

$\dagger$ Significant differences between normoxic and hypoxic ratios $(p<$ $0.05)$.

$¥$ Significant differences between immature and mature values $(p<$ $0.05)$

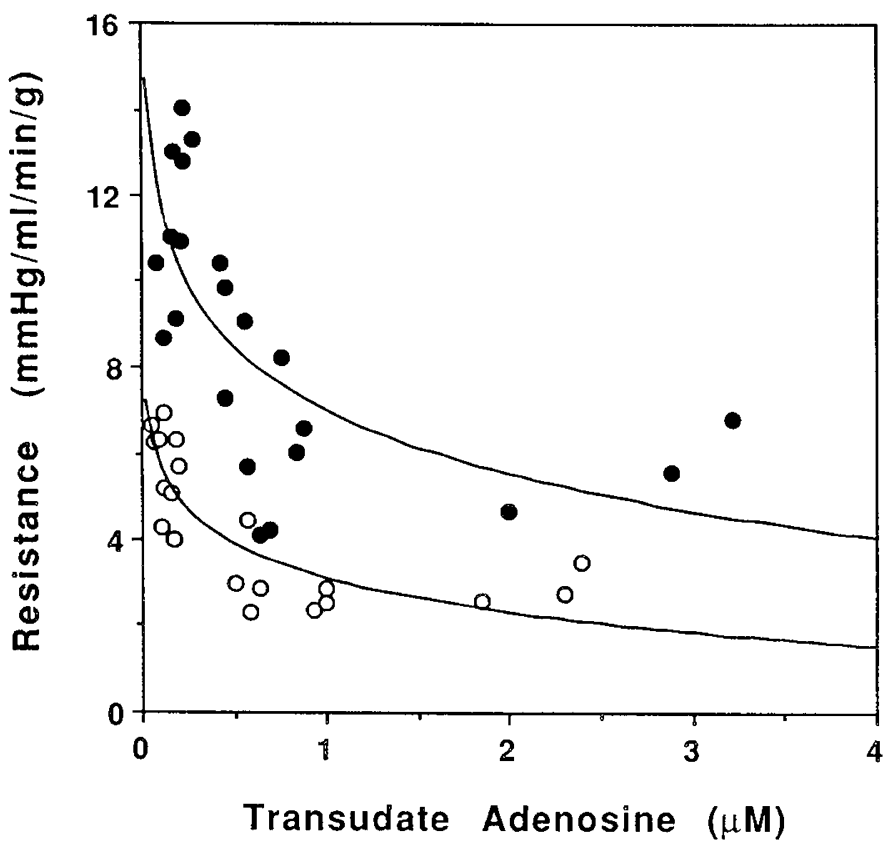

Fig. 1. The correlation of coronary vascular resistance with epicardial adenosine in immature ( $n=10$, open circles $)$ and mature $(n=11$, closed circles) rabbit hearts. All values represent individual data points. The curves shown were fitted with least squares regression analysis $(r=0.69$ and $r=0.84$ for mature and immature hearts, respectively).

have found lower interstitial transudate adenosine levels during normoxia in immature rabbit hearts compared with mature hearts. Hypoxia increased interstitial transudate adenosine in both age groups. During hypoxia, interstitial transudate levels of adenosine were similar in both age groups. However, the immature heart developed higher venous purine levels during hypoxia, indicating that the processes that regulate the release of purines into the venous compartment may differ between age groups.

We have examined developmental differences in the isolated perfused heart, a model that is well established in such studies (26-28). The saline-perfused isolated heart displays the physiologic characteristics of the intact blood-perfused heart. This model also allows the determination of endogenous substances such as adenosine in venous effluent without the effects of red cell metabolism $(27,28)$. We have used rabbit hearts from animals aged 2-4 wk and 4-6 mo, inasmuch as previous investigators have demonstrated functional differences associated with growth and development between these ages $(22,26)$. Additionally, the myocardium of the 2-4 wk-old rabbit is not fully innervated (29) and the immature myocardium of many species has a greater capillary density compared with mature myocardium (8).
Using the isolated heart, we have examined adenosine levels in interstitial transudate and venous effluent. The absence of a direct method for determination of interstitial adenosine levels has been the single largest obstacle to proving or disproving the "adenosine hypothesis" of coronary vasoregulation (1). Most indirect methods for estimating interstitial adenosine (e.g. coronary effluent, cardiac lymph, or pericardial superfusates) significantly underestimate the true interstitial concentration of adenosine because of rapid uptake and metabolism of endogenous adenosine by endothelial cells $(10,11)$. Conversely, total myocardial adenosine overestimates interstitial adenosine, inasmuch as a large proportion of intracellular adenosine is in a bound form $(12,13)$. Recently, a variety of techniques have been described in this laboratory and others for sampling the fluid that collects on the surface of a crystalloid-perfused heart (1419). The "interstitial transudate" adenosine levels that are measured are thought to represent a good index of interstitial adenosine. The present method of using EPD's is simply a variation of previous techniques, allowing equilibration of a small volume of EPD fluid (approximately $3 \mu \mathrm{L}$ per disc) with the interstitial transudate.

Several potential problems arise in the sampling of interstitial transudate in this manner. The mesothelium may transport and metabolize interstitial adenosine, resulting in an underestimate of the true interstitial levels. Fenton et al. (17) have examined mesothelial adenosine metabolism in rats and guinea pigs and found that mesothelial metabolism of adenosine has a minor effect on the concentration of adenosine in the interstitial transudate. Although it is possible that rabbit mesothelium differs regarding its ability to metabolize adenosine, this seems unlikely. Adenosine deaminase may alter interstitial transudate adenosine levels during collection. However, the effects of epicardial adenosine deaminase are thought to be negligible, inasmuch as most of the myocardial adenosine deaminase is located intracellularly, and Fenton et al. (17) have shown that adenosine deaminase activity in interstitial transudate samples represents less than $0.3 \%$ of the total myocardial activity. In addition, preliminary experiments in our laboratory have indicated that there is no significant adenosine deaminase activity in interstitial transudate collected from immature and mature rabbit hearts (see Methods). Finally, it is possible that interstitial transudate represents an index of only the small space beneath the EPD versus a more global index of interstitial fluid. Weinen et al. (30) calculated permeability-surface area products for a number of nonmetabolizable molecules, and the results indicate that interstitial transudate concentrations represent average interstitial solute concentrations for these markers. Although there may be transmural differences in metabolizable substances such as adenosine, the production of transudate from the myocardium as it passes through the interstitium should result in epicardial transudate representing a good index of at least epicardial interstitial adenosine levels. The current sampling technique is simple to use, does not require inversion of the heart $(16,17)$ or construction of special apparatus $(18,19)$, and does not entail the use of large sample volumes.

It has been hypothesized that developmental differences in capillary density might lead to differences in myocardial adenosine (8). We found lower interstitial transudate adenosine during normoxia in support of this hypothesis. However, during hypoxia, no significant differences in interstitial transudate adenosine concentrations were noted between immature and mature hearts despite higher coronary effluent adenosine concentration in the hypoxic immature rabbit heart. Thus, although our results support developmental differences in "resting" adenosine levels in rabbit hearts, they indicate that no significant differences exist in mature and immature hearts during hypoxia. These results conflict somewhat with other studies that report increased venous effluent adenosine levels during norepinephrine stimulation (8) and total myocardial purine levels during ischemia-reperfusion (9) in mature hearts compared with immature hearts. However, 
different indices of adenosine formation were examined in these previous studies and our present study. Jimenez et al. (9) examined the effects of ischemia-reperfusion on total myocardial nucleoside and nucleotide levels, whereas Toma et al. (8) examined venous adenosine formation during norepinephrine infusion. Tissue adenosine overestimates, and venous adenosine underestimates interstitial adenosine, as discussed above. Moreover, it has not been adequately determined whether a linear relationship exists between either of these indices and interstitial adenosine levels. Recent evidence indicates that interstitial and venous adenosine levels can be dissociated under different conditions (17). It should also be noted that Toma et al. (8) examined guinea pig heart as opposed to rabbit hearts. We have previously observed differences in effluent adenosine levels during hypoxia in adult rabbits and adult guinea pigs (Headrick $\mathrm{JH}$, unpublished observations; data not shown) indicating that species differences do exist in venous effluent adenosine formation. Moreover, the newborn rabbit is much more immature than is the newborn guinea pig (31).

The levels of interstitial adenosine obtained in immature hearts $(130 \pm 16 \mathrm{nM})$ and in mature hearts $(228 \pm 35 \mathrm{nM})$ (Table 2$)$ are within the range of values obtained in other isolated heart preparations $(15,17,18)$. Similarly, the $7: 1$ concentration gradient between interstitial transudate and venous effluent levels of adenosine (Table 3 ) is similar in magnitude to previously published results $(15,17)$. This concentration gradient is most likely indicative of rapid endothelial uptake and metabolism of adenosine (32). Hypoxia increased interstitial transudate adenosine to similar levels in both immature $(1180 \pm 231 \mathrm{nM})$ and mature $(1225 \pm 300 \mathrm{nM})$ hearts. On the other hand, venous adenosine increased to a greater extent in immature hearts $(6800 \%)$ than in mature hearts $(2600 \%)$ during the hypoxic period. This led to significantly higher venous adenosine levels in the immature heart (1389 $\pm 207 \mathrm{nM}$ versus $836 \pm 102 \mathrm{nM})$, a difference that was not detected during normoxia.

The disproportionate increase in venous adenosine in the immature hearts could be a result of increased capillary permeability, although this is unlikely in view of the fact that immature hearts accumulated less water during the experiments than did the mature hearts. Another possibility is that endothelial transport and subsequent intracellular adenosine metabolism may differ with age. The appearance of adenosine in the effluent is essentially the balance of release into the interstitium minus endothelial uptake and metabolism (32). Endothelial transport of adenosine is a saturable process $(11,33)$ inhibited by inosine. Endothelial uptake of adenosine is also dependent on the rate of intracellular metabolism. Thus, saturation of intracellular enzymes further inhibits endothelial uptake. Because uptake of adenosine by mature rabbit coronary endothelial cells begins to saturate between 1 and $10 \mu \mathrm{M}$ adenosine (34), and because adenosine kinase and $S$-adenosylhomocysteine synthase in rabbit coronary microvessels saturate at $1-2$ and $0.75 \mu \mathrm{M}$ adenosine, respectively (35), it is highly likely that endothelial uptake is saturated during hypoxia. Adenosine deaminase in rabbit capillaries does not begin to saturate until adenosine approaches 50 to $75 \mu \mathrm{M}$ (35). However, high levels of inosine would act in concert to inhibit the rate of deamination of adenosine during hypoxia. Further studies examing cellular adenosine metabolism in myocytes and endothelial cells will be required to elucidate the mechanism(s) underlying these observations.

The abolition of the concentration gradient for adenosine between the interstitial fluid and the venous effluent in both age groups is evidence that endothelial uptake and metabolism of adenosine does saturate during hypoxia (Table 3), leading to enhanced venous adenosine levels relative to interstitial levels. Other explanations for the abolition of this gradient include enhanced cell death and subsequent release of purines by the endothelium, or increased diffusion through interendothelial gaps. However, both of these mechanisms would also reduce the gradients for inosine and hypoxanthine to a similar degree.
Because the gradient for inosine was unchanged in the mature heart and the gradient for hypoxanthine remained significantly higher than unity, it is unlikely that cell death or changes in passive diffusion play roles in this phenomenon. It is also unlikely that the endothelium releases more adenosine into the venous effluent during hypoxia, inasmuch as it has been previously shown that adenosine release from the endothelium only accounts for $14 \%$ of venous adenosine during normoxia (36) and this percentage contribution decreases with hypoxia (37). Increased interstitial transudate adenosine levels during hypoxia were associated with changes in coronary resistance in both mature and immature hearts (Fig. 1). The correlation between adenosine and resistance is hyperbolic, characteristic of a saturable dose-response relationship. Previous investigators have also demonstrated correlations between endogenous adenosine and coronary vascular resistance $(3,38)$ or coronary flow $(39)$. The relationship between coronary resistance and interstitial transudate adenosine is similar between the immature and mature hearts, with a $50 \%$ reduction of coronary resistance at maximal epicardial adenosine. The different absolute resistance values may indicate a different sensitivity to adenosine in immature hearts, or may simply reflect differences in capillary cross-sectional area (8).

The hemodynamic differences observed between age groups (Table 1) are similar to previous observations. Immature rabbits have a higher resting intrinsic heart rate, lower coronary resistance, and perform less work compared with the mature counterparts $(22,26,40)$. Contractile function in the immature heart was less sensitive to hypoxia, as has been previously reported (40), whereas the bradycardia produced by hypoxia was greater in the immature hearts, similar to results reported by Pridjian et al. (22). The developmental differences in resistance, work, and function in our present study (Table 1) provide evidence that the 2- to 4-wk-old rabbit heart is indeed immature in a number of physiologic processes.

In view of the age-related anatomic differences demonstrated by others $(8,29)$ and the functional differences we have demonstrated, it is not surprising that interstitial transudate adenosine levels are lower in immature hearts compared with mature hearts. However, both age groups had identical myocardial oxygen consumptions and, because these hearts were perfused at similar flows per g myocardium, this should translate into similar oxygen supply:demand ratios. Inasmuch as adenosine production has been linked to myocardial oxygen consumption (41), the oxygen supply:demand ratio $(2,3)$ and myocardial metabolism $(5-7)$, these data imply that there are age-related differences in the link(s) between adenosine formation and myocardial metabolism under basal conditions. In view of the lower interstitial transudate adenosine levels in immature hearts during normoxia, it is surprising that the interstitial transudate adenosine levels were similar in immature and mature hearts during hypoxia despite identical degrees of hypoxia with similar myocardial oxygen consumptions. These data, showing age-related differences in the formation of adenosine under basal conditions but not during hypoxia, imply that there may be two separate processes regulating adenosine formation during normoxic and hypoxic perfusion.

In summary, interstitial transudate adenosine concentrations were lower in immature rabbit hearts compared with mature hearts during normoxia, but during hypoxia they were similar. The relationship between interstitial transudate adenosine and venous adenosine is altered by hypoxia, indicating that venous adenosine levels are an inconsistent index of interstitial adenosine. In addition, the different effects of hypoxia on venous purines in immature hearts implies that there are age-related differences in the processes regulating venous purine release during hypoxia. Finally, coronary vascular resistance correlates well with interstitial transudate adenosine in adult and immature hearts during normoxia and hypoxia, supporting the proposal 
that endogenous adenosine is involved in the metabolic regulation of coronary blood flow (1).

Acknowledgments. The authors thank Dr. Robert D. Abbot, Ph.D. for his statistical expertise and Carol Newcomb for her secretarial assistance.

\section{REFERENCES}

1. Berne RM 1980 The role of adenosine in the regulation of coronary blood flow. Circ Res 47:807-813

2. Sparks HV, Bardenheuer H 1986 Regulation of adenosine formation by the heart. Circ Res 58:193-20

3. Bardenheuer H, Schrader J 1986 Supply-to-demand ratio for oxygen determines formation of adenosine by the heart. Am J Physiol 250:H173-H180

4. Portman MA, Heineman FW, Balaban RS 1989 Developmental changes in the relation between phosphate metabolites and oxygen consumption in the sheep heart in vivo. J Clin Invest 83:456-464

5. He MX, Wangler RD, Dillon PF, Romig GD, Sparks HV 1987 Phosphorylation potential and adenosine release during norepinephrine infusion in guinea pig heart. Am J Physiol 253:H1184-H1191

6. Kiviluoma KT, Peuhkurinen KJ, Hassinen IS, 1986 Role of cellular energy state and adenosine in the regulation of coronary flow during variation in contraction frequency in an isolated perfused heart. J Mol Cell Cardiol 18:1133-1142

7. Headrick J, Clarke K, Willis RJ 1989 Adenosine production and energy metabolism in ischemic and metabolically stimulated rat heart. $\mathbf{J}$ Mol Cell Cardiol 21:1089-1100

8. Toma BS, Wangler RD, Sparks HV 1988 Metabolic hyperemia is reduced in adult vs immature guinea pig hearts. Am J Physiol 255:H1460-H1467

9. Jimenez E, del Nido P, Nakamura H, Sarin M, Levitsky S, Feinberg H 1989 Developmental changes in adenine metabolism with ischemia/reperfusion in the rabbit heart. J Mol Cell Cardiol 21 (Suppl II):S.27

10. Nees S, Gerlach E 1983 Adenine nucleotide and adenosine metabolism in cultured coronary endothelial cells: formation and release of adenine compounds and possible functional implications. In: Berne RM, Rall TW, Rubio R (eds) Regulatory Function of Adenosine. Martinus Nijhoff, The Hague, pp $347-360$

11. Pearson JD, Carleton JS, Hutching A, Gorman JL 1978 Uptake and metabolism of adenosine by pig aortic endothelial and smooth-muscle cells in culture. Biochem J 170:265-271

12. Olsson RA, Saito D, Steinheart CR 1982 Compartmentalization of the adenosine pool of dog and rat hearts. Circ Res 50:617-626

13. Schrader JW, Schultz W, Bardenheuer H 1981 Role of s-adenosyl homocysteine hydrolase in adenosine metabolism of mammalian heart. Biochem $\mathrm{J}$ 196:65-70

14. Soracco CA, Tribble CG, Gidday J, Belardinelli L, Rubio R, Berne RM 1989 Validation of epicardial porous discs for estimation of cardiac interstitial fluid adenosine. FASEB J 3:A406(abstr)

15. Decking UKM, Eberhard J, Kammermeier H 1988 Interstitial transudate concentration of adenosine and inosine in rat and guinea pig hearts. Am J Physiol 254:H1125-H1132

16. Fenton RA, Dobson Jr JG 1987 Measurement by fluorescence of interstitial adenosine levels in normoxic, hypoxic, and ischemic perfused rat hearts. Circ Res 60:177-184

17. Fenton RA, Tsimikas S, Dobson Jr JG 1990 Influence of $\beta$-adrenergic stimulation and contraction frequency on rat heart interstitial adenosine. Circ Res $66: 457-468$

18. Heller LJ, Mohrman DE 1988 Estimates of interstitial adenosine from surface exudates of isolated rat hearts. J Mol Cell Cardiol 20:509-523
19. Imai S, Chin W-P, Jin H, Nakazawa M 1989 Production of AMP and adenosine in the interstitial fluid compartment of the isolated perfused normoxic guinea pig heart. Pflugers Arch 414:443-449

20. Magovern JA, Pae Jr WE, Miller CA, Waldhausen JA 1989 The mature and immature heart: response to normothermic ischemia. J Surg Res 46:366369

21. Harkness JE, Wagner JE 1989 The Biology and Medicine of Rabbits and Rodents. Lea, Febiger, Philadelphia, p 10

22. Pridjian AK, Levitsky S, Krukenkamp I, Silverman NA, Feinberg H 1987 Developmental changes in reperfusion injury. J Thorac Cardiovasc Surg 93:428-433

23. Wei HM, Kang YH, Merrill GF 1989 Canine coronary vasodepressor responses to hypoxia are abolished by 8-phenyltheophylline. Am J Physiol 257:H1043$\mathrm{H} 1048$

24. Karwatowska-Prokopczuk E Ciabattoni G, Wennmalm A 1989 Effects of hydrodynamic forces on coronary production of prostacyclin and purines. Am J Physiol 256:H1532-H1538

25. Nakamura KT, Alden BM, Matherne GP, Jose PA, Robillard JE 1988 Ontogeny of renal hemodynamic response to terbutaline and forskolin in sheep. J Pharmacol Exp Ther 247:453-459

26. Parrish MD, Ayres NA, Kendrick BT, Fixler DE 1986 Maturational differences in the isolated isovolumic rabbit heart. Am J Physiol 251:H1143-H1148

27. Toma BS, Wangler RD, DeWitt DF, Sparks HV 1985 Effect of developmen on coronary vasodilator reserve in the isolated guinea pig heart. Circ Res 57:538-544

28. Buss DD, Hennemann III WW, Posner P 1987 Maturation of coronary responsiveness to exogenous adenosine in the rabbit. Basic Res Cardiol 82:290-296

29. Friedman WF, Pool PE, Jacobwitz D, Seagren SC, Braunwald E 1968 Sympathetic innervation of the developing rabbit heart: biochemical and histochemical comparisons of fetal, neonatal, and adult myocardium. Circ Res 23:25-32

30. Weinen W, Kammermeier H 1988 Intra- and extracellular markers in interstitial transudate of perfused rat hearts. Am J Physiol 254:H785-H794

31. Duckles SP, Banner Jr W 1984 Changes in vascular smooth muscle reactivity during development. Annu Rev Pharmacol Toxicol 24:65-83

32. Wangler RD, Gorman MW, Wang CY, Dewitt DF, Chan IS, Bassingthwaighte JB, Sparks HV 1989 Transcapillary adenosine transport and interstitial adenusine concentration in guinea pig hearts. Am J Physiol 257:H89-H106

33. Rovetto MJ, Ford DA, Yassin A 1987 Cardiac myocyte and coronary endothelial cell adenosine transport. In: Gerlach E, Becker BF (eds) Topics and Perspectives in Adenosine Research. Springer-Verlag, Berlin, pp 188-198

34. Belloni FL, Liang BC, Gerritsen ME 1987 Effects of alkylxanthines and calcium antagonists on adenosine uptake by cultured rabbit coronary microvascular endothelium. Pharmacology 35:1-15

35. Mistry G, Drummond GI 1986 Adenosine metabolism in microvessels from heart and brain. J Mol Cell Cardiol 18:13-22

36. Kroll K, Schrader J, Piper HM, Henrich M 1987 Release of adenosine and cyclic AMP from coronary endothelium in isolated guinea pig hearts: relation to coronary flow. Circ Res 60:659-665

37. Deussen A, Moser G, Schrader J 1986 Contribution of coronary endothelial cells to cardiac adenosine production. Pflugers Arch 406:608-614

38. Rubio R, Wiedmeier VT, Berne RM 1974 Relationship between coronary flow and adenosine production and release. $\mathrm{J}$ Mol Cell Cardiol 6:561-566

39. Schrader J, Haddy FJ, Gerlach E 1977 Release of adenosine, inosine and hypoxanthine from the isolated guinea pig heart during hypoxia, flowautoregulation and reactive hyperemia. Pflugers Arch 369:1-6

40. Bove EL, Stammers AH 1986 Recovery of left ventricular function after hypothermic global ischemia. J Thorac Cardiovasc Surg 91:115-122

41. Foley DH, Herlihy JT, Thompson CI, Rubio R, Berne RM 1978 Increased adenosine formation by rat myocardium with acute aortic constriction. J Mol Cell Cardiol 10:293-300 